\title{
Changing basal insulin from NPH to detemir or glargine in patients with type I diabetes and a history of severe hypoglycemia
}

\author{
Odd Erik Johansen' \\ Pål Johan Vanberg' \\ Bente Kvarv Kilhovd ${ }^{2}$ \\ Anders Palmstrøm \\ Jørgensen' \\ 'Medical Department, Asker \\ and Baerum Hospital, RUD, Norway; \\ ${ }^{2}$ Department of Endocrinology, Aker \\ University Hospital, OSLO, Norway
}

Correspondence: Odd Erik Johansen Medical department,Asker and Baerum Hospital, PO BOX 83, I 309 RUD,

Norway

Tel +4797817674

Fax +4767550993

Email odd.erik.johansen@broadpark.no
Background: The insulin analogs, glargine and detemir, are associated with reduced hypoglycemia incidence compared with NPH insulin. We assessed the impact of changing basal insulin from NPH to glargine or detemir in patients with type 1 diabetes mellitus who experienced severe hypoglycemia.

Material and methods: A retrospective chart review was conducted that included 73 (31 female) patients (mean age 48 years, diabetes duration 19 years) treated for 12 to 24 months with insulin glargine $(n=43)$ or detemir $(n=30)$.

Results: There were no patients who withdrew from treatment due to side effects. The mean treatment duration in both groups was 18 months. Changing from NPH insulin was associated with a $-0.3 \%(p=0.036)$ reduction in HbAlc for glargine (baseline $8.8 \%)$ and $-0.4 \%(p=0.040)$ for detemir (baseline 8.3\%) treated patients; insulin dosages increased, respectively by $4.1(\mathrm{p}=0.045)$ and 4.3 units $(\mathrm{p}=0.004)$ (mean values). Weight did not increase significantly and the 1-year rate of serious hypoglycemia was $0.25 /$ person/year.

Conclusion: Switching from NPH-insulin to insulin detemir or glargine in type 1 diabetes mellitus patients with previous serious hypoglycemia was associated with a reduction in $\mathrm{HbA} 1 \mathrm{c}$. However, severe hypoglycemia was not completely eliminated, and few patients reached internationally accepted glycemic treatment goals.

Literature search: We searched Medline, PubMed (with key search terms type 1 diabetes, NPH insulin, detemir, glargine and serious hypoglycemia), reference lists and databases of ongoing and completed trials (through July 2008) provided from the manufacturers of the drugs to identify relevant literature.

Keywords: type 1 diabetes mellitus, insulin, observational study, HbA1c, efficacy

\section{Introduction}

Neutral protamine Hagedorn (NPH) insulin is the most widely used basal insulin worldwide. ${ }^{1}$ However, NPH insulin may not be the optimal basal insulin due to its significant day-to-day variability, bell-shaped effect curve and estimated 12- to 15-hour duration of action. ${ }^{2,3}$ In addition, being a suspension of crystals, it needs proper re-suspension, a fact that is often disregarded by patients. ${ }^{4}$ These characteristics of NPH-insulin render patients more prone to hypoglycemia and usually require the users to be on a twice daily injection schedule to attain 24-hour basal insulin coverage. ${ }^{3} \mathrm{NPH}$ insulin is also associated with weight gain, ${ }^{5}$ thus further reducing potential compliance. ${ }^{6}$ These are all factors that are barriers for achieving good glycemic control.

These shortcomings of NPH insulin spurred the development of other basal insulin formulations, of which two are currently marketed: insulin glargine (Lantus ${ }^{\circledR}$; Sanofi Aventis, France); and insulin detemir (Levemir ${ }^{\circledR}$; Novo Nordisk, Denmark). Glargine is synthesized via the substitution of glycine for asparagine at position A21 of the insulin molecule and the addition of two arginine molecules at position B30;, detemir is 
acylated with a fatty-acid chain (myristic acid) to the lysine at residue B29 of the insulin molecule which mediates albumin binding in the interstitial fluid and plasma., ${ }^{2,9}$ Both come in a clear solution and do not require re-suspension.

Although none of the basal insulin analogs have a completely "flat" pharmacokinetic profile, ${ }^{3}$ the modulations of the human insulin molecule inherent in detemir and glargine contribute to a "flatter" and more protracted pharmacodynamic profile, with significantly lower withinsubject variability, compared with NPH insulin., ${ }^{210}$ In randomized controlled trials (RCT) comparing these insulin analogs with NPH insulin, insulin glargine and detemir demonstrated similar reductions in $\mathrm{HbA} 1 \mathrm{c}$ and fasting plasma glucose compared to NPH insulin. Further, the use of these long-acting analogs has also been associated with fewer hypoglycemic episodes, particularly nocturnal hypoglycemia, and has also been associated with less weight gain (especially for detemir) than NPH insulin. , $, 11,12,13,14^{2}$

For these reasons, governmental authorities and/or other payers (eg, insurance companies) in several industrialized countries around the globe (eg, Sweden, Finland, Denmark, UK, US, Australia, Canada, Germany, Spain, France, South Africa) have granted general reimbursement for detemir and glargine in type 1 diabetes mellitus (T1DM), and in some regions their use has exceeded that of NPH insulin. In Norway however, this is currently not the case. The final decision for whether a medicine in Norway will be added to the drug reimbursement formulary lies with the parliament. However, the Norwegian Medicines Agency has the authority to grant reimbursement without consent of the Parliament if the estimated annual increase in cost for national insurance is less than NOK 5 million (approximately US $\$ 0.8$ million) for the 5 years following the approval of such reimbursement. ${ }^{15}$

The Parliament bases their decision on advice from the Norwegian Medicines Agency and the Ministry of Health and Social Affairs who evaluate all applications regarding medical and health economic issues. There are four possible outcome of this process: reimbursement denied (as is the case for orlistat); full reimbursement (as is the case for NPH insulin and all short acting insulin analogs); restricted reimbursement (limited to a certain numbers of prescriptions per year as is currently is the case for the glitazones), ${ }^{15}$ and reimbursement on a named basis, which means individual patient application for reimbursement and evaluation is on a case by case basis. ${ }^{18}$ The latter option currently prevails in Norway for the long-acting insulin analogs. However, the likelihood for a patient to obtain this product reimbursed is restricted since the application must come from a specialist in internal medicine or paediatrics. Additionally, it is required that NPH insulin has previously has been tried and that the patient experienced either frequent, or serious nocturnal, hypoglycemic episode(s) or blood glucose variations to an extent that limits optimal glycemic control. ${ }^{17}$ Patients in Norway with T1DM who receive long-acting insulin analogs by the reimbursement system must therefore be more difficult to manage than patients included in other studies; whether previous RCT results also are applicable to this patient group remains uncertain. We therefore decided to undertake evaluation of the long-term impact on $\mathrm{HbAlc}$ in patients with T1DM and at least one documented episode of serious hypoglycemia whose basal insulin prescription was changed from NPH to detemir or glargine. Secondarily, we evaluated the impact of such a change in basal insulin on weight gain, insulin dosage and administration, drug side effects and the frequency of serious hypoglycemic episodes.

\section{Materials and methods Inclusion criteria and data collection}

This retrospective chart review was performed at the diabetic outpatient clinic at Asker and Baerum Hospital (a secondary referral centre in eastern Norway that serves 150,000 residents), where approximately 800 patients with DM receive regular follow-up. Care of T1DM patients is facilitated by a physician or diabetes nurse specialist visit at either 3- or 6-month intervals; these visits include assessment of body weight, $\mathrm{HbAlc}$, lipids, plasma glucose, hemoglobin, creatinine, and insulin regimen (dosage, time and numbers of injections). In addition episodes of serious hypoglycemia (defined as an event requiring assistance of another person to actively administer carbohydrate, glucagon, or other resuscitative actions) ${ }^{18}$ are recorded. Patients are referred to an ophthalmologist on a yearly basis and urine albumin excretion rate is evaluated annually. Patients are typically advised to regulate their bolus insulin dosages as needed according to meal composition and influence of any physical activity, alcohol consumption or other factors known to effect insulin needs; the goal is to maintain 2-hour postprandial, fasting and bedtime glucose levels in the range of 4 to $8 \mathrm{mmol} / \mathrm{L}$ $(72-144 \mathrm{mg} / \mathrm{dL})$. If these goals are not achieved, we recommend that evening, or morning (or both), basal insulin doses are titrated in steps of 2 units (every third day), until respective blood glucose levels are within target range.

Inclusion criteria in this retrospective chart review were: age > 18 years; T1DM; regular use of insulin glargine or detemir prescription for 12 to 24 months between Dec 2003 and Dec 2007; history of episodes of severe hypoglycemia as 
per the definition noted above. Exclusion criteria were prior basal insulin use other than NPH-insulin and T2DM.

Subjects eligible for inclusion were identified by authors and personnel at the outpatient clinic. Data from the charts were consistently collected by two persons (authors, OEJ and PJV) and data analysis was conducted by OEJ so as to minimize bias. Results were interpreted after consultation among all authors.

\section{Collection and analysis of blood samples}

Venous blood samples are drawn between 8 and 10 AM after an overnight fast, within 7 days prior to outpatient clinic visits and are analyzed within 24 hours at the central laboratory of the hospital. Plasma glucose is analysed by utilization of the glucose hexokinase method and HbA1c (upper normal reference value of $6.2 \%$ ) is analyzed utilizing colorimetric and immunoturbidimetrical methods (Cobas Integra, Roche Diagnostics GmbH, Mannheim, Germany). Serum levels of total cholesterol, high-density lipoprotein (HDL)-cholesterol and triglycerides (TG) are measured enzymatically on a Roche/ Hitachi 917 analyzer (Roche Diagnostics GmbH, Mannheim, Germany) whereas low-density lipoprotein (LDL) cholesterol is calculated using the Friedewald formula.

\section{Statistical analysis}

Based on 2 studies with similar design (a Finnish switch study reporting data for 62 subjects treated for 12 months and a Japanese switch study reporting data for 72 subjects treated for 18 months) we estimated that we in total needed a minimum of 72 subjects treated for a minimum of 12 , and a maximum of 24, months with either insulin glargine or insulin detemir ${ }^{19,20}$ in order to evaluate the long term impact of basal insulin switch according to HbAlc results.

Data analysis was performed using SPSS statistical software version 14.0.1 for Windows (SPSS Inc.). Results for continuous variables are presented as mean and standard deviation unless otherwise stated and categorical variables are presented as counts or proportions (\%). Since there was no randomization in this survey we did not perform any between-group comparisons. Comparisons for continuous data were performed with a paired t-test and Pearson bivariate correlation. Comparisons between categorical variables were carried out by chi-squared or Fisher exact test. P-values are 2 -sided and considered significant when $<0.05$.

\section{Results}

In total, 98 patients with DM were found to have used a long-acting insulin analog in the defined period (31.12.2003 to
31.12.2007). Among these, 9 had type 2 DM, 7 were missing initiation data, 1 person used a non-NPH based basal insulin (insulin pump) and 8 had been prescribed insulin analog treatment for a period of less than 12 months. Hence, in total, 73 patients were eligible for analysis, 43 who received a prescription for insulin glargine and 30 for insulin detemir.

The mean follow-up period from initiation of detemir or glargine treatment to last observation was $18 \pm 6$ (minimum 12 , maximum 24) months in both groups. Generally, the patients who had been prescribed these insulins were characterized by relatively long diabetes duration (18 years) and had a relatively high prevalence of micro- and macro-vascular complications (Table 1).

Table 2 shows the insulin regimens that were used at the time of switching to a long-acting insulin analog. Ninety-three percent of subjects used NPH insulin in a twice-daily regimen, $99 \%$ had at least one injected dose of bolus insulin whereas $58 \%$ injected bolus insulin $\geq 4$ times per day (ie, breakfast, lunch, dinner, evening meal as well as with snacks).

The change to detemir was associated with a statistically significant, $-0.4 \%$ (95\% confidence interval [CI] $(-0.7,-0.1), \mathrm{p}=0.04)$, reduction in HbA1c among subjects (baseline $8.3 \%$ ) and the change to glargine was associated with a $-0.3 \%(95 \% \mathrm{CI}(-0.6,-0.1), \mathrm{p}=0.036)$ reduction (baseline 8.8\%) (Figure 1a). However, the switch did not increase the proportion of patients with $\mathrm{HbA} 1 \mathrm{c} \leq 7.0 \%$ (ie, 3 and 5 patients before switching to glargine or detemir and, respectively, 4 and 6 after 1 year).

Table 3 details the half-yearly changes in long-acting and bolus insulin dosages, as well as changes in HbA1c, throughout 24 months. All patients using glargine started with a once-daily regimen (32 [74\%] in the evening); however, after 24 months, 33\% used a twice-daily regimen. Correspondingly, $20 \%$ of the detemir users initiated usage with once-daily regimen, but after 24 months, all were following a twice-daily regimen.

Mean insulin detemir and glargine dosages increased, respectively by 4.3 units (U) $(95 \%$ CI $(1.5,7.1), p=0.004)$ and $4.1 \mathrm{U}(95 \% \mathrm{CI}(0.1,8.1), \mathrm{p}=0.045)$, while the bolus insulin dosage did not (Figure 1b). Weight increased, but not in a statistically significant manner, in both groups (Figure 1a): $0.8(95 \% \mathrm{CI}(-1.7,3.3), \mathrm{p}=0.515) \mathrm{kg}$ in the glargine- and $0.3 \mathrm{~kg}(95 \% \mathrm{CI}(-3.4,4.0), \mathrm{p}=0.877)$ in the detemir-treated group.

No correlations were noted between baseline weight and changes in $\mathrm{HbA} 1 \mathrm{c}$, or between baseline weight and changes in weight. However, a significant negative correlation was seen between baseline HbAlc and the reduction 
Table I Background data and glycemic and lipid parameters (before changing basal insulin analogs) for 73 patients with TIDM treated with a long-acting insulin analog (detemir or glargine) for 12 to 24 months

\begin{tabular}{|c|c|c|c|c|}
\hline & & $\begin{array}{l}\text { All } \\
(n=73)\end{array}$ & $\begin{array}{l}\text { Detemir } \\
(n=30)\end{array}$ & $\begin{array}{l}\text { Glargine } \\
(n=43)\end{array}$ \\
\hline \multicolumn{5}{|l|}{ Background } \\
\hline \multicolumn{2}{|l|}{ Age (year) } & $48(17,83)$ & $52(23,78)$ & $46(17,83)$ \\
\hline \multirow{2}{*}{\multicolumn{2}{|c|}{ Gender (male/female) }} & $42(58 \%) /$ & $16(53 \%) /$ & $26(61 \%) /$ \\
\hline & & 31 (42\%) & 14 (47\%) & 17 (39\%) \\
\hline \multicolumn{2}{|c|}{ Diabetes duration (year) } & $19(1,54)$ & $26(1,54)$ & $14(2,45)$ \\
\hline \multicolumn{2}{|l|}{ Weight (kg) } & $78.3(49.4,131.0)$ & $81.4(5|.0| 3 \mid .0)$, & $76.4(49.4,105.0)$ \\
\hline \multicolumn{2}{|l|}{$\mathrm{BMI}\left(\mathrm{kg} / \mathrm{m}^{2}\right)$} & $25.9(16.9,42.8)$ & $27.2(22.9,42.8)$ & $25.3(16.9,33.0)$ \\
\hline \multicolumn{5}{|c|}{ Microvascular complications } \\
\hline \multicolumn{2}{|l|}{ Retinopathy } & $25(34 \%)$ & $16(53 \%)$ & $9(21 \%)$ \\
\hline \multicolumn{2}{|l|}{ Neuropathy } & $16(22 \%)$ & $8(27 \%)$ & $8(19 \%)$ \\
\hline \multicolumn{2}{|c|}{ Albuminuria (micro/macro) } & 24 (33\%) & II (37\%) & $13(30 \%)$ \\
\hline \multicolumn{5}{|c|}{ Other complications } \\
\hline \multicolumn{2}{|c|}{$\begin{array}{l}\text { Cerebro, peripheral or } \\
\text { coronary artery disease }\end{array}$} & $27(37 \%)$ & I5 (50\%) & $12(28 \%)$ \\
\hline \multicolumn{2}{|c|}{ Thyroid disorder } & $9(12 \%)$ & $3(10 \%)$ & $6(14 \%)$ \\
\hline \multicolumn{5}{|c|}{ Medications other than insulin } \\
\hline \multicolumn{2}{|l|}{ Statins } & $32(44 \%)$ & $18(60 \%)$ & 14 (33\%) \\
\hline \multicolumn{2}{|c|}{ Platelet inhibitor } & 17 (23\%) & $9(30 \%)$ & $8(19 \%)$ \\
\hline \multicolumn{2}{|c|}{ ACE-inhibitor/ AT-II receptor } & 31 (44\%) & $17(57 \%)$ & 14 (33\%) \\
\hline \multicolumn{5}{|c|}{ blocker } \\
\hline \multicolumn{2}{|l|}{ Diuretics } & 13 (I8\%) & $6(20 \%)$ & $7(16 \%)$ \\
\hline \multicolumn{5}{|c|}{ Laboratory parameters } \\
\hline \multicolumn{2}{|l|}{$\mathrm{HbAlc}(\%)$} & $8.6(5.7, I I .7)$ & $8.3(5.7, \mathrm{I} I .3)$ & $8.8(6.8,11.7)$ \\
\hline \multirow[t]{2}{*}{ Glucose } & $\mathrm{mmol} / \mathrm{L}$ & II.6 $(2.4,24.0)$ & $10.7(2.4,18.5)$ & $12.2(3.2,24.0)$ \\
\hline & $\mathrm{mg} / \mathrm{dL}$ & $208.8(43.2,432.0)$ & I $92.6(43.2,333.0)$ & $219.6(57.6,432.0)$ \\
\hline \multirow{2}{*}{$\begin{array}{l}\text { Total } \\
\text { cholesterol }\end{array}$} & $\mathrm{mmol} / \mathrm{L}$ & $4.8(3.0,7.6)$ & $4.9(3.6,6.3)$ & $4.8(3.0,7.6)$ \\
\hline & $\mathrm{mg} / \mathrm{dL}$ & $186(116,294)$ & $189(139,244)$ & $186(116,294)$ \\
\hline \multirow{2}{*}{$\begin{array}{l}\text { LDL- } \\
\text { cholesterol }\end{array}$} & $\mathrm{mmol} / \mathrm{L}$ & $2.6(I . I, 4.4)$ & $2.5(1.2,3.5)$ & $2.6(1.1,4.4)$ \\
\hline & $\mathrm{mg} / \mathrm{dL}$ & $101(43,170)$ & $97(46,135)$ & I0I $(43, \mid 70)$ \\
\hline \multirow{2}{*}{$\begin{array}{l}\text { HDL- } \\
\text { cholesterol }\end{array}$} & $\mathrm{mmol} / \mathrm{L}$ & I.7 $(0.9,2.9)$ & $1.9(1.2,2.9)$ & $1.6(0.9,2.8)$ \\
\hline & $\mathrm{mg} / \mathrm{dL}$ & $66(35,112)$ & $73(46,112)$ & $62(35,112)$ \\
\hline \multirow[t]{2}{*}{ Triglycerides } & $\mathrm{mmol} / \mathrm{L}$ & I.I $(0.4,2.7)$ & $0.9(0.4,2.1)$ & I.2 $(0.4,2.7)$ \\
\hline & $\mathrm{mg} / \mathrm{dL}$ & $97(35,239)$ & $78(35,186)$ & $106(35,239)$ \\
\hline \multicolumn{2}{|c|}{ Hemoglobin (g/dL) } & I4.I $(10.8,16.3)$ & $14.2(1 \mid .0,16.3)$ & $14.0(10.8,16.2)$ \\
\hline \multicolumn{2}{|c|}{ Creatinine $(\mu \mathrm{mol} / \mathrm{L})$} & $76(4 I, 153)$ & $75(44,1$ I 8$)$ & $77(4|| 53)$, \\
\hline
\end{tabular}

Note: Data given as mean (min., max.) for numerical and $\mathrm{n}(\%)$ for categorical parameters.

Abbreviations: ACE, angiotensin converting enzyme; AT-II, angiotensin II; HbA Ic, hemoglobin A Ic; LDL, low density lipoprotein; HDL, high density lipoprotein.

in $\mathrm{HbA1c}$ for both detemir $(\mathrm{r}=-0.657, \mathrm{p}<0.001)$ and glargine $(r=-0.507, p=0.001)$. There was also a significant correlation between the increase in insulin dose and reduction in $\mathrm{HbA} 1 \mathrm{c}$ for detemir $(\mathrm{r}=0.439, \mathrm{p}=0.025)$, but not for glargine $(r=0.236, p=0.160)$.

During the first 12 months, 15 patients experienced a total of 18 serious hypoglycemic episodes, which translates to 0.25 episodes/person year during treatment and such occurrences were similarly distributed among the two groups.

One patient was hospitalized due to ketoacidosis after 6 months of detemir treatment and 2 non-hypoglycemic side effects were observed. One patient developed edema and joint achiness immediately after the initiation of glargine, and 
Table 2 Details of insulin treatment regimens prior to changing basal insulin from NPH to detemir or glargine

\begin{tabular}{|c|c|c|c|}
\hline & All $(n=73)$ & Detemir $(n=30)$ & Glargine $(n=43)$ \\
\hline \multicolumn{4}{|l|}{ Basal insulin (NPH) } \\
\hline Daily insulin dosage $(U)$ & $30(10,80)$ & $28(10,74)$ & $31(12,80)$ \\
\hline \multicolumn{4}{|l|}{ Number of injections (n) } \\
\hline 1 & $5(7 \%)$ & $3(10 \%)$ & $2(5 \%)$ \\
\hline 2 & $68(93 \%)$ & $27(90 \%)$ & $4 \mathrm{I}(95 \%)$ \\
\hline \multicolumn{4}{|l|}{ Bolus insulin } \\
\hline Human insulin (n) & $7(10 \%)$ & $2(7 \%)$ & $5(12 \%)$ \\
\hline Insulin analog (n) & 65 (89\%) & $28(93 \%)$ & 37 (86\%) \\
\hline No bolus insulin (n) & I (I\%) & $0(0 \%)$ & I (2\%) \\
\hline Daily insulin dosage $(U)$ & $24(0,80)$ & $25(10,80)$ & $24(0,72)$ \\
\hline \multicolumn{4}{|l|}{ Number of injections (n) } \\
\hline 0 & I (I\%) & $0(0 \%)$ & I (2\%) \\
\hline 1 & $4(6 \%)$ & I (3,3\%) & $3(7 \%)$ \\
\hline 2 & $6(8 \%)$ & $2(6,7 \%)$ & $4(9 \%)$ \\
\hline 3 & $20(27 \%)$ & $6(20 \%)$ & 14 (33\%) \\
\hline$\geq 4$ & 42 (58\%) & 21 (70\%) & 21 (49\%) \\
\hline
\end{tabular}

Note: Data given as mean (min., max.) for numerical and $\mathrm{n}(\%)$ for categorical parameters.

Abbreviation: $U$, international unit.

1 developed a local injection site reaction after 21 months of treatment on detemir. None of these events necessitated treatment withdrawal.

\section{Discussion}

This retrospective chart review on the use of long-acting insulin analogs over a period of 12 to 24 months in 73 patients with T1DM who had had at least 1 documented episode of serious hypoglycemia, demonstrates that changing from $\mathrm{NPH}$ insulin to detemir or glargine improved glycemic control with corresponding decreases in $\mathrm{HbA} 1 \mathrm{c}$ levels of $-0.3 \%$ to $0.4 \%$. The fact that $\mathrm{HbA} 1 \mathrm{c}$ levels were not even more dramatically improved may be related to lack of application of a strict treatto-target algorithm, as in contrast to those in the RCT, ${ }^{13,14}$ and that the T1DM patients included in this analysis probably are not representative for all patients with T1DM (ie, due to the inclusion criterion), hence their diabetes is possibly more difficult to manage. Predictors for $\mathrm{HbAlc}$ improvements were high $\mathrm{HbAl} \mathrm{c}$ and a positive insulin dosage titration. Interestingly, similar levels of $\mathrm{HbAlc}$ reduction was achieved with similar increases in insulin dose for both insulin analogs, which is at variance with some head-to-head RCTs where higher detemir dosages were needed. ${ }^{21,22}$ There was also the statistically insignificant correlation between $\mathrm{HbAlc}$ reduction and weight increase, which is a well-established side effect of NPH-insulin, ${ }^{5}$ although this finding must be cautiously interpreted.
The impact of these insulin analogs on glycemic control in the current study population is consistent with results from other observational studies documenting a change from NPH to other basal insulins, ${ }^{19,22,23}$ although conflicting data also exist. One recent publication reports that 62 adolescents treated with glargine for 12 months in Finland had no change in $\mathrm{HbA} 1 \mathrm{c}$ (ie, $9.2 \%$ both at initiation and 12 months). ${ }^{20}$ A similar conclusion was recently drawn in a Cochrane review article where no glycemic benefit of long-acting insulin analogs was found compared with intermediate-acting insulin, ${ }^{24}$ although a beneficial effect on both nocturnal and severe hypoglycemia was noted, with odds ratios of respectively 0.70 (95\% CI 0.63-0.79) and 0.73 (95\% CI 0.61-0.87). However, it should be noted that this report included studies of relatively short duration, and it is unknown if conclusions would change if studies of longer duration were included.

Serious hypoglycemia was not eliminated after the change from NPH insulin to the detemir or glargine, and still occurred at a prevalence of 0.25 person year of treatment. In a 9- to 12-month long observational study in the UK, the corresponding rate of serious hypoglycemia among patients with T1DM (mean HbA1c 7.8\%, diabetes duration 30 years) was 3.2. ${ }^{25}$ Hence the hypoglycemia rate seen seems low in our survey and is in line with the findings from the Cochrane review, ${ }^{24}$ but this variance could be related to uncertainties or discrepancies in collection and reporting procedures, in addition to differences in patient characteristics and 


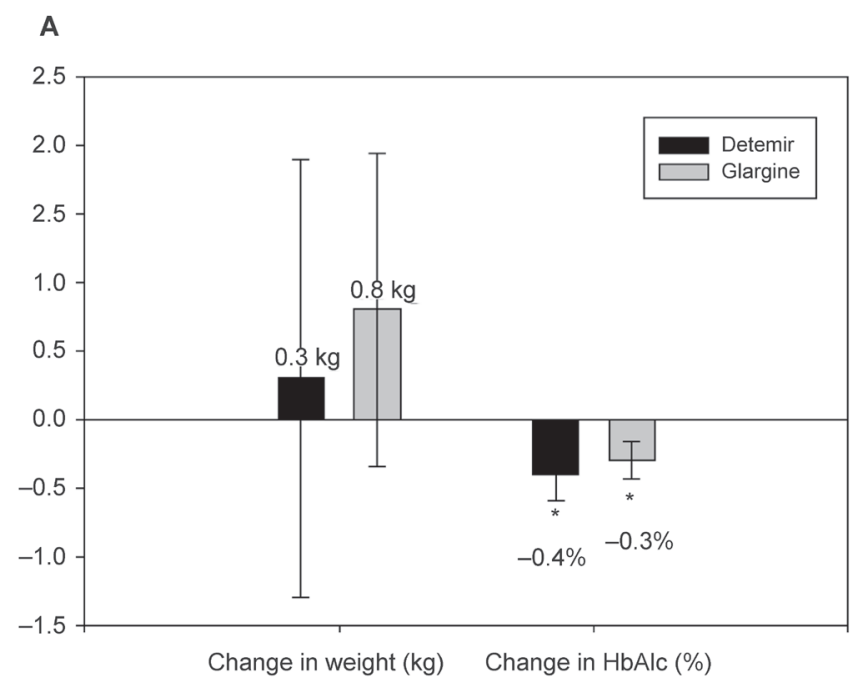

B

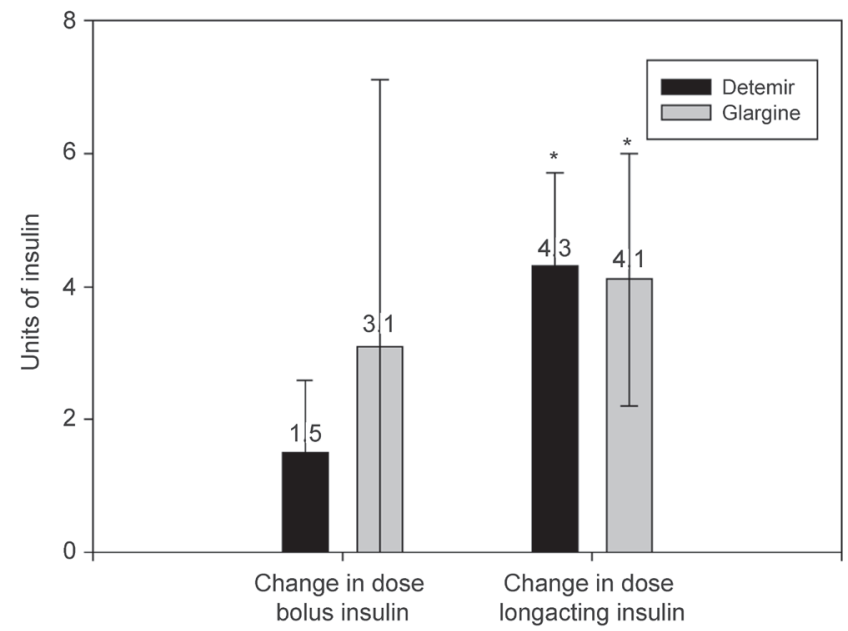

Figure I Mean change from initial to last observation for 73 patients with TIDM treated with insulin detemir ( $\mathrm{n}=30$; mean duration of observation, I8 months) and glargine $(\mathrm{n}=43$; mean duration of observation, 18 months) in a) weight $(\mathrm{kg})$ and $\mathrm{HbAlc}(\%)$ and $\mathbf{b})$ bolus- and long-acting insulin dosages. Bars indicate mean and standard error. $*_{p}<0.05$ from baseline.

hypoglycemia occurrence rate as we did not register this rate prior to the switch.

Of interest is also that one third of the patients treated with glargine throughout the 2-year period used it twice daily. This is at variance with the Summary of Product Characteristics (SmPC), stating that glargine should be administrated once daily, while detemir can be administered once or twice daily. This finding is, however, supported by other reports indicating that glargine twice daily is in fact needed in 25\% to $33 \%$ of adult patients with T1DM..$^{26,27,28}$

In conclusion, although the proportion of patients who attained optimal glycemic control (ie, $\leq 7.0 \%$ by $\mathrm{HbAlc}$ ) was low, serious hypoglycemic episodes were not completely eliminated, the current analyses are limited by being retrospective, are not corrected for the impact of possible confounding factors and were conducted on a limited number of patients, we believe that a $0.3 \%$ to $0.4 \%$ reduction in $\mathrm{HbAlc}$, and results indicating a relatively low 1 -year rate of serious hypoglycemia, are of clinical interest. The improvements noted are important, not only due to the preventive effect on micro- and macrovascular complications, ${ }^{29}$ but more so in improving quality of life. ${ }^{24,30}$ On the other hand, this study also underscores the fact that long-acting insulin analogs alone do not solve the problem related to achieving optimal glycemic control and additional tools are needed for the treatment armamentarium for this particular group of patients.

\section{Acknowledgments}

We thank Dr Rolf Whitfield, Dr Harald Smith and the diabetes nurse specialists, Elsa Orvik, Beate Sørgård and 


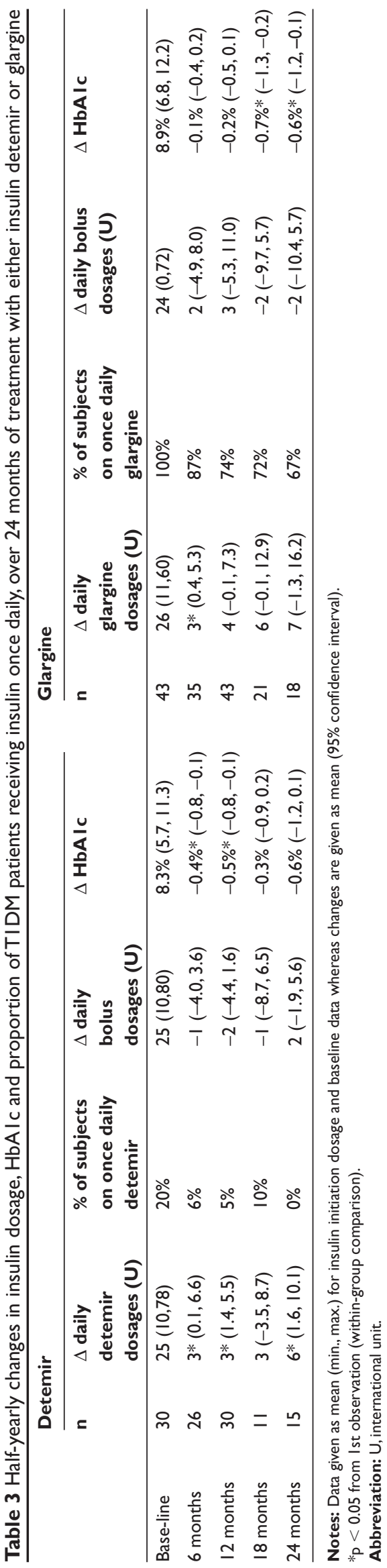

Elisabeth Holmen Berg for their contribution in collecting the data.

\section{Disclosures}

All authors have received lecture honoraria and travel grants from, and/or participated in clinical trials of, Sanofi-Aventis and Novo Nordisk. OEJ was an employee of Novo Nordisk from 2006 to 2007.

\section{References}

1. Ogle G, Beran D, Raab R, Deeb L. On behalf of the Task Force on Insulin, Test Strips and Other Diabetes Supplies. Global access to and availability of insulin. Diabetes Voice. 2006;51:22-25.

2. Hirsch IB. Insulin analogues. N Engl J Med. 2005;352:174-183.

3. Heise T, Pieber TR. Towards peakless, reproducible and long-acting insulins. An assessment of the basal analogues based on isoglycaemic clamp studies. Diabetes Obes Metab. 2007;5:648-659.

4. Jehle PM, Micheler C, Jehle DR, et al. Inadequate suspension of neutral protamine Hagendorn (NPH) insulin in pens. Lancet. 1999;354:1604-1607.

5. Larger E. Weight gain and insulin treatment. Diabetes Metab. 2005;31:4S51-4S56.

6. Peyrot M, Rubin RR, Lauritzen T, et al. Resistance to insulin therapy among patients and providers: results of the cross-national Diabetes Attitudes, Wishes, and Needs (DAWN) study. Diabetes Care. 2005;28:2673-2679.

7. Barnett AH. Insulin glargine in the treatment of type 1 and type 2 diabetes. Vasc Health Risk Manag. 2006;2:59-67.

8. Havelund S, Plum A, Ribel U, et al. The mechanism of protraction of insulin detemir, a long-acting, acylated analog of human insulin. Pharm Res. 2004;21:1498-1504.

9. Philips JC, Scheen A. Insulin detemir in the treatment of type 1 and type 2 diabetes. Vasc Health Risk Manag. 2006;2:277-283.

10. Heise T, Nosek L, Rønn BB et al. Lower within-subject variability of insulin detemir in comparison to NPH insulin and insulin glargine in people with type 1 diabetes. Diabetes. 2004;53:1614-1620.

11. Rosenstock J, Dailey G, Massi-Benedetti M, et al. Reduced Hypoglycemia Risk With Insulin Glargine: A meta-analysis comparing insulin glargine with human NPH insulin in type 2 diabetes. Diabetes Care. 2005;28:950-955.

12. Hermansen K, Davies M, Derezinski T, et al. A 26-week, randomized parallel, treat-to-target trial comparing insulin detemir with NPH insulin as add-on therapy to oral glucose-lowering drugs in insulin-naïve people with type 2 diabetes. Diabetes Care. 2006;29:1269-1274.

13. Chatterjee S, Jarvis-Kay J, Rengarajan T et al. Glargine versus NPH insulin: efficacy in comparison with insulin aspart in a basal bolus regimen in type 1 diabetes - the glargine and aspart study (GLASS) a randomised cross-over study. Diabetes Res Clin Pract. 2007;77:215-222.

14. Bartley PC, Bogoev M, Larsen J, et al. Long-term efficacy and safety of insulin detemir compared to Neutral Protamine Hagedorn insulin in patients with Type 1 diabetes using a treat-to-target basal-bolus regimen with insulin aspart at meals: a 2-year, randomized, controlled trial. Diabet Med. 2008;25:442-449.

15. Report No. 18 to the Storting (2004-2005). On course towards more correct use of medicine - Medicinal Product Policy. Accessed Nov 13th 2008.URL: http://www.regjeringen.no/Upload/HOD/ Dokumenter\%20LMS/Utdrag\%20fra\%20legemiddelmeldingen\%20o versatt $\% 20$ ti $\% 20$ engelsk.pdf.

16. Levorsen A, Kristiansen IS, Aasland OG. Physicians' experience with increased use of individual reimbursement for pharmaceuticals. Tidsskr Nor Laegeforen. 2008;128:1829-1832. 
17. The Norwegian Labour and Welfare Organisation 2008. Accessed Sept 6th 2008. URL: http://rundskriv.nav.no/rtv/lpext.dll?f=templates\& $\mathrm{fn}=$ main-j.htm\&2.0.

18. Workgroup on Hypoglycemia, American Diabetes Association. Defining and reporting hypoglycemia in diabetes: a report from the American Diabetes Association Workgroup on Hypoglycemia. Diabetes Care. 2005;28:1245-1249.

19. Kanazawa Y, Igarashi Y, Komiya K, et al. Long-term efficacy of insulin glargine after switching from NPH insulin as intensive replacement of basal insulin in Japanese diabetes mellitus. Comparison of efficacy between type 1 and type 2 diabetes (JUN-LAN Study 1.2). Endocr J. 2007;54:975-983.

20. Päivärinta M, Tapanainen P, Veijola R. Basal insulin switch from NPH to glargine in children and adolescents with type 1 diabetes. Pediatr Diabetes. 2008;9:83-90.

21. Pieber TR, Treichel H-C, Hompesch B, et al. Comparison of insulin detemir and insulin glargine in subjects with Type 1 diabetes using intensive insulin therapy. Diabet Med. 2007;24:635-642.

22. www.novonordisk-trials.com. 2008. Safety and efficacy of insulin detemir plus insulin aspart against insulin glargine plus insulin aspart as mealtime insulin in type 1 diabetes. Accessed May 8th 2008. URL: http://www.novonordisk-trials.com/website/search/trial-result-details. aspx?id $=1057 \& \mathrm{p}=1 \&$ search $=\mathrm{t}()$

23. Currie CJ, Poole CD, Tetlow T, et al. The outcome of care in people with type 1 and type 2 diabetes following switching to treatment with either insulin glargine or insulin detemir in routine general practice in the UK: a retrospective database analysis. Curr Med Res Opin. 2007;23(S1):33-39.

24. Dornhorst A, Lüddeke HJ, Honka M, et al. Safety and efficacy of insulin detemir basal-bolus therapy in type 1 diabetes patients: 14-week data from the European cohort of the PREDICTIVE study. Curr Med Res Opin. 2008;24:369-376.
25. Vardi M, Jacobson E, Nini A, Bitterman H. Intermediate acting versus long acting insulin for type 1 diabetes mellitus. Cochrane Database Syst Rev. 2008;16;(3):CD006297.

26. UK Hypoglycaemia Study Group. Risk of hypoglycaemia in types 1 and 2 diabetes: effects of treatment modalities and their duration. Diabetologia. 2007;50:1140-1147.

27. Albright ES, Desmond R, Bell DS. Efficacy of conversion from bedtime NPH insulin injection to once- or twice-daily injections of insulin glargine in type 1 diabetic patients using basal/bolus therapy. Diabetes Care. 2004;27:632-633.

28. Ashwell SG, Gebbie J, Home PD. Twice-daily compared with oncedaily insulin glargine in people with Type 1 diabetes using meal-time insulin aspart. Diabet Med. 2006;23:879-886.

29. Garg S, Gottlieb PA, Hisatomi ME, et al. Improved glycemic control without an increase in severe hypoglycemic episodes in intensively treated patients with type 1 diabetes receiving morning, evening, or split dose insulin glargine. Diab Res Clin Pract. 2004;66:49-56.

30. Nathan DM, Cleary PA, Backlund JY, et al. Intensive diabetes treatment and cardiovascular disease in patients with type 1 diabetes. $N$ Engl J Med. 2005;353:2643-2653.

31. Ashwell SG, Bradley C, Stephens JW, et al. Treatment satisfaction and quality of life with insulin glargine plus insulin lispro compared with NPH insulin plus unmodified human insulin in people with Type 1 diabetes. Diabetes Care. 2008;31:1112-1117. 